\title{
Large-Conductance Calcium-Activated Potassium Channels Facilitate Transmitter Release in Salamander Rod Synapse
}

\author{
Jian Wei Xu and Malcolm M. Slaughter \\ Department of Physiology and Biophysics, State University of New York at Buffalo, Buffalo, New York 14214
}

\begin{abstract}
Large-conductance calcium-activated potassium (BK) channels are colocalized with calcium channels at sites of exocytosis at the presynaptic terminals throughout the nervous system. It is expected that their activation would provide negative feedback to transmitter release, but the opposite is sometimes observed. Attempts to resolve this apparent paradox based on alterations in action potential waveform have been ambiguous. In an alternative approach, we investigated the influence of this channel on neurotransmitter release in a nonspiking neuron, the salamander rod photoreceptors. Surprisingly, the BK channel facilitates calcium-mediated transmitter release from rods. The two presynaptic channels form a positive coupled loop. Calcium influx activates the BK channel current, leading to potassium efflux that increases the calcium current. The normal physiological voltage range of the rod is well matched to the dynamics of this positive loop. When the rod is further depolarized, then the hyperpolarizing BK channel current exceeds its facilitatory effect, causing truncation of transmitter release. Thus, the calcium channel-BK channel linkage performs two functions at the synapse: nonlinear potentiator and safety brake.
\end{abstract}

Key words: facilitation; retina; ion channel; synaptic transmission; calcium channel; BK; positive coupling; salamander; ribbon synapse

\section{Introduction}

Neurotransmitter release is regulated directly by voltage-gated Ca channels localized at presynaptic terminals (Katz and Miledi, 1968). Many other ion channels are also found at the presynaptic terminals (Meir et al., 1999). Large-conductance calciumactivated potassium (BK) channels are of special interest because they are ubiquitous at presynaptic terminals in many types of neurons (Robitaille et al., 1993; Knaus et al., 1996; Sakaba et al., 1997; Meir et al., 1999; Hu et al., 2001; Skinner et al., 2003). However, the role of $\mathrm{BK}$ channels in synaptic transmission is ambiguous, and the mechanism remains unresolved. The BK channel is activated by both Ca entry into the cell and by membrane depolarization. As a hyperpolarizing channel, its block or genetic removal is expected to increase transmitter release. This was observed in some systems (Robitaille et al., 1993; Marshall et al., 1994; Wang et al., 2001). However, the opposite has been found in others (Warbington et al., 1996; Pattillo et al., 2001; Skinner et al., 2003), and no effect has also been reported (Lindgren and Moore, 1989; Hu et al., 2001). It has been proposed that BK channel block affects transmitter release by prolongation of action potential repolarization (Hu et al., 2001; Pattillo et al., 2001). Action potential broadening by BK channel block is often observed in neuron somas (Lancaster and Nicoll, 1987; Storm, 1987a,b; Shao et al., 1999; Hu et al., 2001). However,

\footnotetext{
Received May 14, 2004; revised July 11, 2005; accepted July 12, 2005.

This work was supported by National Eye Institute Grant 05725 to M.M.S. We thank Anil Neelakantan for technical help.

Correspondence should be addressed to Jian Wei Xu, Department of Physiology and Biophysics, State University of New York at Buffalo, 124 Sherman Hall, 3435 Main Street, Buffalo, NY 14214. E-mail: jxu@acsu.buffalo.edu or jwxujerry@yahoo.com.

DOI:10.1523/JNEUROSCI.1572-05.2005

Copyright $\odot 2005$ Society for Neuroscience $\quad$ 0270-6474/05/257660-09\$15.00/0
}

Hu et al. (2001) found that blocking BK channels did not change the action potential shape at the axon terminal, although it did so at the soma. Pattillo et al. (2001) observed that BK channel blockers suppressed transmitter release without significantly altering action potential shape in the presynaptic varicosities of frog neuromuscular junction.

BK channels are expressed in retinal ribbon synapses, including photoreceptor and bipolar cell terminals (Barnes and Hille, 1989; Sakaba et al., 1997; Llobet et al., 2003). In bipolar cells, BK channels are tightly coupled to Ca channels and sites of exocytosis (Sakaba et al., 1997; Llobet et al., 2003). We investigated the role of BK channels in synaptic transmission at ribbon synapses of vertebrate rod photoreceptors. Rods do not have prominent sodium currents. Therefore, BK channel effects on synaptic transmission can be assessed in the absence of action potentials, and the complications of fast kinetics are eliminated. Rods in tiger salamander retina, unlike cones, do not receive horizontal cell feedback. Therefore, the confounding factor of feedback synapses is also avoided (Attwell et al., 1983).

We found that BK channels facilitate transmitter release from rods. The results suggest that BK channel activity increases the local extracellular potassium concentration inside the synaptic cleft, which in turn enhances $\mathrm{Ca}$ channel currents. Therefore, BK channels and $\mathrm{Ca}$ channels can form a positive coupled loop to amplify synaptic transmission.

\section{Materials and Methods}

Preparations and recordings. Larval tiger salamanders were obtained from Kons Direct (Germantown, WI) and Charles Sullivan (Nashville, TN) and were kept in tanks maintained at $4^{\circ} \mathrm{C}$ on a $12 \mathrm{~h} \mathrm{light/dark} \mathrm{cycle.}$ Retinal slices were prepared as described previously (Wu, 1987; Awatra- 
mani and Slaughter, 2000). All procedures were performed in accordance with the United States Animal Welfare Act and the National Institutes of Health Guide for the Care and Use of Laboratory Animals (publication 85-23) and were approved by the University Animal Care Committee. All operations were performed under infrared illumination to keep the retina fully dark adapted.

To prepare isolated retinal neurons, a similar dissection procedure and a standard dissociation procedure were used, as detailed previously (Mitra and Slaughter, 2002).

Recordings were made using the whole-cell patch technique. Secondorder neurons were identified by their response characteristics and their appearance after staining with Lucifer yellow. The slices or isolated cells were bathed continuously with control Ringer's solution containing the following (in mM): $111 \mathrm{NaCl}, 2.5 \mathrm{KCl}, 1.8 \mathrm{CaCl}_{2}, 1 \mathrm{MgCl}_{2}, 10$ dextrose, and 5 HEPES, buffered to $\mathrm{pH} 7.8$. Unless stated, the recording pipettes contained the following (in $\mathrm{mm}$ ): $100 \mathrm{~K}$-gluconate, $5 \mathrm{NaCl}, 2 \mathrm{MgCl}_{2}, 5$ EGTA, 5 HEPES, and $0.1 \%$ Lucifer yellow, buffered to $\mathrm{pH} 7.4$ with $\mathrm{KOH}$. In addition, the pipette solution contained $4 \mathrm{~mm}$ ATP, $20 \mathrm{~mm}$ phosphocreatine, and $50 \mathrm{U} \mathrm{ml}^{-1}$ creatine phosphokinase to maintain ATP inside the cell. To record Ca channel current in isolated rods, the Ringer's solution was changed to one containing $5 \mathrm{~mm} \mathrm{BaCl}_{2}$ and $40 \mathrm{~mm}$ tetraethylammonium (TEA)-Cl in equal molar replacement of some of the $\mathrm{NaCl}$ and all of the $\mathrm{CaCl}_{2}$.

To study the effect of $\left[\mathrm{K}^{+}\right]_{\mathrm{o}}$ on $I_{\mathrm{Ca}}$, the Ringer's solution was changed to one containing $5 \mathrm{~mm} \mathrm{CsCl}$ and $40 \mathrm{~mm}$ TEA-Cl in equal molar replacement of $\mathrm{NaCl}$. Five millimolar $\mathrm{CsCl}$ was used to block the hyperpolarization-activated current $\left(I_{\mathrm{h}}\right)$ (Wollmuth and Hille, 1992). $\mathrm{KCl}$ concentration was $2.5 \mathrm{~mm}$ in the control solution. To raise $\left[\mathrm{K}^{+}\right]_{\mathrm{o}}$, $\mathrm{KCl}$ replaced equal molar $\mathrm{NaCl}$. One hundred millimolar Csmethanesulfonate replaced K-gluconate in the pipette solution.

To test for potential direct effects of BK channel blockers [charybdotoxin (CTX), iberiotoxin, or $1 \mathrm{~mm}$ TEA] on Ca channel current, we used an external solution containing the following (in mM): $109 \mathrm{NaCl}, 2.5 \mathrm{KCl}$, $5 \mathrm{BaCl}_{2}, 1 \mathrm{MgCl}_{2}, 10$ dextrose, and 5 HEPES. Ba is the charge carrier of the Ca channel current and also blocks BK current. However, to completely block the BK current, it was necessary to add 10 mM BAPTA, a fast Ca chelator, to the internal solution. One hundred millimolar Csmethanesulfonate replaced K-gluconate in the pipette solution.

Electrophysiological data were collected with a List EPC-9 amplifier (HEKA Elektronik, Lambrecht/Pfalz, Germany), HEKA Pulse software, and a Macintosh G3 computer (Apple Computers, Cupertino, CA) and analyzed with Igor Pro software (WaveMetrics, Lake Oswego, OR). The analog signals were filtered at $5 \mathrm{kHz}$. Data are expressed as means \pm SEs. Access resistance was 8-15 $\mathrm{M} \Omega$ and generally was not compensated. However, BK current at depolarized voltages was often bigger than $1 \mathrm{nA}$, which created a voltage error $>10 \mathrm{mV}$. These errors were calculated and voltage corrections were made when $I-V$ curves were generated. Liquid junction potential was measured to be around $-10 \mathrm{mV}$, and this value adjustment was applied to all the data.

Second-order neurons in salamander retina can be classified into roddominant and cone-dominant cells (Hensley et al., 1993). We used a green light stimulus (wavelength, $500 \mathrm{~nm}$ ) with an intensity of $\sim 10^{3}$ photons $/ \mu \mathrm{m}^{2}$ per second. At this intensity, no response could be recorded in cones ( $n=5$; data not shown). The cells we chose to analyze responded very well to this stimulus, indicating they received mainly rod input.

Calculation of increase of $\left[\mathrm{K}^{+}\right]_{o}$ caused by BK channel activity. If a single BK channel is open at the cleft for $1 \mathrm{~ms}$, the total number of ions extruded into the cleft is the following: $N=g \times\left(V_{\mathrm{m}}-E_{\mathrm{v}}\right) \times t / e$, where $N$ is total ion number, $g$ is the single-channel conductance, $V_{\mathrm{m}}$ is membrane potential, $E_{\mathrm{v}}$ is reversal potential of $\mathrm{K}$, and $e$ is the unitary charge. If we assign $g=150 \mathrm{pS}$ (Li et al., 2003), $V_{\mathrm{m}}=-40 \mathrm{mV}, E_{\mathrm{v}}=-95 \mathrm{mV}, t=1$ $\mathrm{ms}, e=1.6 \times 10^{-19}$ coulombs, then $N \approx 5 \times 10^{4}$. This number of ions spread in a thin cylinder of the rod synaptic cleft, approximate diameter of $2 \mu \mathrm{m}$ and height of $10 \mathrm{~nm}$ (Townes-Anderson et al., 1985), would increase potassium ion concentration by $\sim 3 \mathrm{~mm}$.
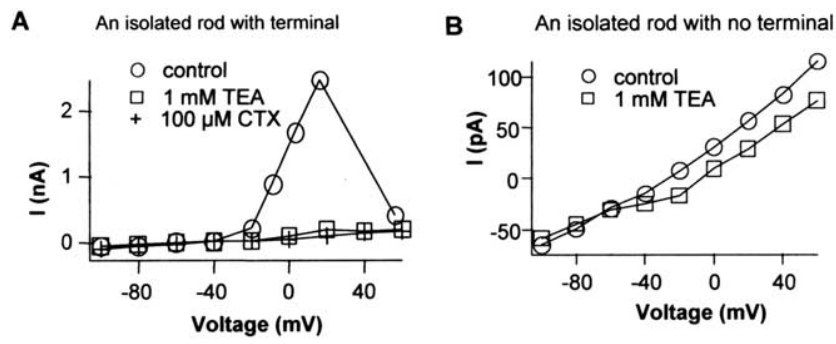

C

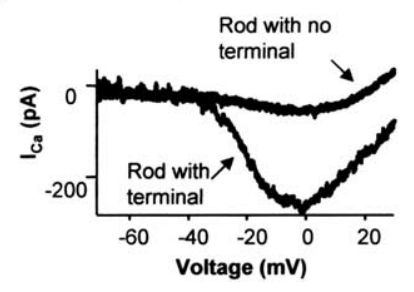

D

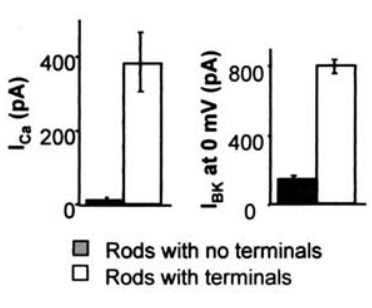

Figure 1. BK and Ca conductances are concentrated in rod photoreceptor terminals. $A, I-V$ relationship of an isolated rod with intact synaptic terminals measured at the end of $80 \mathrm{~ms}$ pulses. A large outward current was activated at around $-40 \mathrm{mV}$ and reached peak at $\sim 20 \mathrm{mV}$. This current was blocked by BK channel blockers $100 \mu \mathrm{m}$ charybdotoxin plus $1 \mathrm{~mm}$ TEA. Step voltages were corrected for access resistance (see Materials and Methods). $\boldsymbol{B}, I-V$ relationship of an isolated rod with no synaptic terminal had much smaller outward currents. The currents blocked by BK channel blockers were a small part of the total current. $C$, Examples of $I_{\mathrm{Ca}_{\mathrm{a}}}$ of isolated rods with or without terminals measured by a voltage ramp $(-70-30 \mathrm{mV}$ at $1 \mathrm{mV} /$ $\mathrm{ms}$ ). Five millimolar $\mathrm{Ba}^{2+}$ was the charge carrier. D, Comparison of $\mathrm{BK}$ and $\mathrm{Ca}$ channel currents in isolated rods with and without terminals. The amplitude of BK current was the outward current evoked by a step to $0 \mathrm{mV}$ that was blocked by BK channel blockers. The mean BK currents of rods with or without synaptic terminals were $795 \pm 40$ and $138 \pm 27 \mathrm{pA}$, respectively ( $n=$ 7 for each). The mean peak calcium currents of isolated rods with and without terminals were $380 \pm 82$ and $12 \pm 8 \mathrm{pA}$, respectively ( $n=6$ for each). Error bars represent SE.

\section{Results}

\section{$\mathrm{BK}$ and Ca channels localized at rod terminal}

We found that most $\mathrm{BK}$ and $\mathrm{Ca}$ channels are concentrated at the rod synaptic terminal. Acutely isolated rods were recorded, and they were divided into two groups: one that retained their synaptic terminals and the other that lost their terminals during dissociation. Rods with terminals showed large outward currents at positive voltages (Fig. 1A). The outward current was activated at around $-40 \mathrm{mV}$ and reached peak at $\sim 20 \mathrm{mV}$. It starts to decline after $20 \mathrm{mV}$, which corresponds with a decrease of Ca driving force and hence less Ca influx. This voltage profile is characteristic of Ca-activated potassium channels. BK channel blockers charybdotoxin (100 nM), TEA (1 mM), and iberiotoxin (20 nM; data not shown) blocked most of the outward current (Fig. 1A). In isolated rods that lost their terminals, the outward BK current was greatly reduced (Fig. $1 \mathrm{~B}$ ). Iberiotoxin is a specific BK channel blocker and has no effect on other K channels (Galvez et al., 1990). Charybdotoxin blocks BK and intermediate Ca-K channels (Miller et al., 1985; Grissmer et al., 1993) and also Shakertype K channel (MacKinnon et al., 1988). One millimolar TEA blocks not only BK (Iwatsuki and Petersen, 1985) but also other voltage-gated $\mathrm{K}$ channels (e.g., Kv1.1, Kv3.1, and KCNQ2) (Christie et al., 1990; Grissmer et al., 1993, 1994; Hadley et al., 2000). In all the experiments, we found the effects of these three blockers were equivalent.

Similarly, comparing the voltage-gated calcium current in isolated rods with and without axon terminals indicates that most of the Ca current was also concentrated at the synaptic terminal (Fig. 1C). Based on comparisons of rods with and without axon 
terminals, $>80 \%$ of BK and $95 \%$ of Ca current are concentrated at the synaptic terminal (Fig. $1 D$ ). A similar BK channel distribution was also found in goldfish bipolar cell terminals (Sakaba et al., 1997).

To approximate the number of $\mathrm{Ca}$ channels at the terminal, we estimated the L-type Ca channel conductance is $10 \mathrm{pS}$ in salamander photoreceptors, the mean open probability $\left(P_{\mathrm{o}}\right)$ is 0.10 at $0 \mathrm{mV}$ (Thoreson et al., 2000) and the reversal potential is $+130 \mathrm{mV}$. Thoreson et al. (2000) measured the single-channel conductance of Ca to be $22 \mathrm{pS}$ when using $82 \mathrm{~mm} \mathrm{Ba}^{2+}$ as the charge carrier. We used $5 \mathrm{~mm} \mathrm{Ba}^{2+}$, yielding lower conductance values, probably close to $10 \mathrm{pS}$ (Rosenberg et al., 1988). The average Ca channel current at the terminal was 360 pA (96\% of $380 \mathrm{pA}$ ) at $0 \mathrm{mV}$, leading to an estimate of $\sim 2800$ total Ca channels at the rod terminal.

A similar calculation was used to estimate the number of BK channels at the terminal. The conductance of retinal BK channels is estimated to be $150 \mathrm{pS}$ ( $\mathrm{Li}$ et al., 2003). The $P_{\mathrm{o}}$ depends on transmembrane voltage and local intracellular calcium concentration. Free intracellular $\mathrm{Ca}$ in depolarized rods is probably between 1 and $10 \mu \mathrm{M}$ (Heidelberger et al., 1994; Rieke and Schwartz, 1996). From single-channel recordings, $P_{\mathrm{o}}$ is 0.25 at $0 \mathrm{mV}$ when free intracellular calcium is $10 \mu \mathrm{M}$ ( $\mathrm{Li}$ et al., 2003). The average $I_{\mathrm{BK}}$ at the terminal was $657 \mathrm{pA}$ (83\% of $\left.795 \mathrm{pA}\right)$, yielding an estimate of $\sim 200 \mathrm{BK}$ channels at the rod synaptic terminal.

The rod synaptic terminal can be approximated as a pocket with diameter of $1 \mu \mathrm{m}$, corresponding to the invagination of the rod ribbon synapse (Townes-Anderson et al., 1985). If all the channels were localized to this pocket, then average channel densities at the terminal would be 240 and 17 per $\mu \mathrm{m}^{2}$ for Ca and BK channels, respectively. This assumes even channel distribution on the terminal, although it is likely that the distribution is biased toward the site of the ribbon synapse.

\section{BK channel block suppressed transmitter release from rods}

Rods are relatively depolarized in the dark, with a dark membrane potential around $-40 \mathrm{mV}$. At this voltage, a number of $\mathrm{Ca}$ and BK channels are activated. When a light stimulus is applied, the cell is hyperpolarized as a result of the closure of cGMP-gated channels in the outer segment, and $\mathrm{Ca}$ and BK channels deactivate. If the effect of BK channel activation is primarily as a current carrier, then BK channel block is expected to increase the transmitter release of the rod and the amplitude of light response by depolarizing the rod in the dark.

To test this expectation, we recorded light-evoked EPSCs from second-order neurons in dark-adapted retinal slices. There are three types of second-order neuron. Glutamate, released from photoreceptors in the dark, depolarizes Off-bipolar and horizontal cells and hyperpolarizes On-bipolar cells. Second-order neurons receive both rod and cone input in salamander retina, and they can be classified as rod-dominant and cone-dominant cells (Hensley et al., 1993). We used a green light stimulus (wavelength, $500 \mathrm{~nm}$ ) with an intensity $\sim 10^{3}$ photons $/ \mu \mathrm{m}^{2}$ per second. At this intensity, no response was recorded in cones (five of five; data not shown). The second-order cells we chose to analyze responded well to this stimulus, indicating they received mainly rod synaptic input.

Unexpectedly, BK channel blockers suppressed the lightevoked EPSC amplitudes in all three types of second-order neuron (Fig. $2 \mathrm{~A}$ ). The cells were held at $-60 \mathrm{mV}$, a voltage at which BK channel open probability is very low. Therefore, the EPSC changes produced by BK channel blockers most likely reflect a decrease of presynaptic transmitter release. Furthermore, in On- bipolar cells the dark holding current became more negative, but in Off-bipolar and horizontal cells holding current was more positive (Fig. $2 A, B$ ). These opposite polarity effects can be most easily explained if BK channel blockers reduced rod transmitter release in the dark.

We also measured the dark membrane conductance change after the application of BK channel blockers (Fig. 2 B). Secondorder neurons were held at $-60 \mathrm{mV}$ and stepped to $-70 \mathrm{mV}$ while kept in the dark. Under these conditions, most of the membrane conductance is produced by glutamate receptor channels, whereas voltage-activated channels are not affected by this voltage step. Blocking BK channels reduced the conductance in Offbipolar and horizontal cells but increased the conductance of On-bipolar cells. These opposite polarity effects are consistent with the changes in EPSCs and demonstrate that blocking BK channels suppresses rod transmitter release.

Similar effects on light response and dark holding current were observed when inhibitory amino acid receptors were blocked with $100 \mu \mathrm{M}$ picrotoxin $\left(\mathrm{GABA}_{\mathrm{A}}\right.$ and $\mathrm{GABA}_{\mathrm{C}}$ receptor antagonist) and $10 \mu \mathrm{M}$ strychnine (glycine receptor antagonist). This eliminates the possibility that the BK effects are caused by inhibitory feedback, which is not anticipated in rods (Attwell et al., 1983). Therefore, we conclude that blocking rod synaptic BK channels decreased their transmitter release.

How do BK channel blockers reduce transmitter release? One possible mechanism is that they reduce the light response amplitude of rods. To test this, voltage responses to light stimuli were recorded in rods in current-clamp mode. BK channel blockers had little effect on the dark membrane potential or light responses of the majority of rods (Fig. 3A) (the exceptions are described in Fig. 3B). Under control conditions, the average dark membrane potential of rods was $-41.8 \pm 1.3 \mathrm{mV}(n=13)$. In the presence of BK channel blockers, it was $-42.4 \pm 1.4 \mathrm{mV}$. The change was not statistically significant. Thus, BK channel blockers can reduce rod transmitter release while having a negligible effect on rod dark membrane potential or light response properties.

BK channel blockers only affected the light responses of rods that exhibited a spike-like overshoot during the recovery phase (4 of 13 cells) (Fig. 3B). The spike was Ca dependent and eliminated by $30 \mu \mathrm{M}$ nifedipine, an L-type Ca channel blocker (Fig. 3B, bottom trace). BK channel blockers increased the peak of the calcium spike from $-27.6 \pm 2.7$ to $-17.4 \pm 3.0 \mathrm{mV}(n=4)$ (Fig. $3 B)$. This result fits the traditional role of $\mathrm{BK}$ channels of limiting membrane depolarization but is not its primary function at the rod synapse.

\section{BK channel block suppressed Ca currents in rods}

Blocking BK channels reduced transmitter release from rods but had little effect on its voltage responses to light. These results led to the hypothesis that the BK channels may affect the activity of $\mathrm{Ca}$ channels at the rod synapse. To study Ca channel current, one normally needs to block all potassium current to unmask the $\mathrm{Ca}$ current. This obviously cannot be applied while investigating BK channels. To our advantage, Ca current could be observed in most rods without applying potassium channel blockers in retinal slices (Fig. 4A). During a voltage ramp from -70 to $-10 \mathrm{mV}$, an inward current was activated at $-45 \mathrm{mV}$ and peaked at -25 $\mathrm{mV}$. The inward current was produced by Ca channels because it was blocked by $50 \mu \mathrm{M} \mathrm{Cd}^{2+}$, a Ca channel blocker (Fig. $4 \mathrm{~A}$ ). The current blocked by $\mathrm{Cd}^{2+}$ is shown on the right panel of Figure $4 A$, obtained by subtracting the control current and the current in $\mathrm{Cd}^{2+}$. It is biphasic, inward at -45 to $-25 \mathrm{mV}$ and outward at 
A

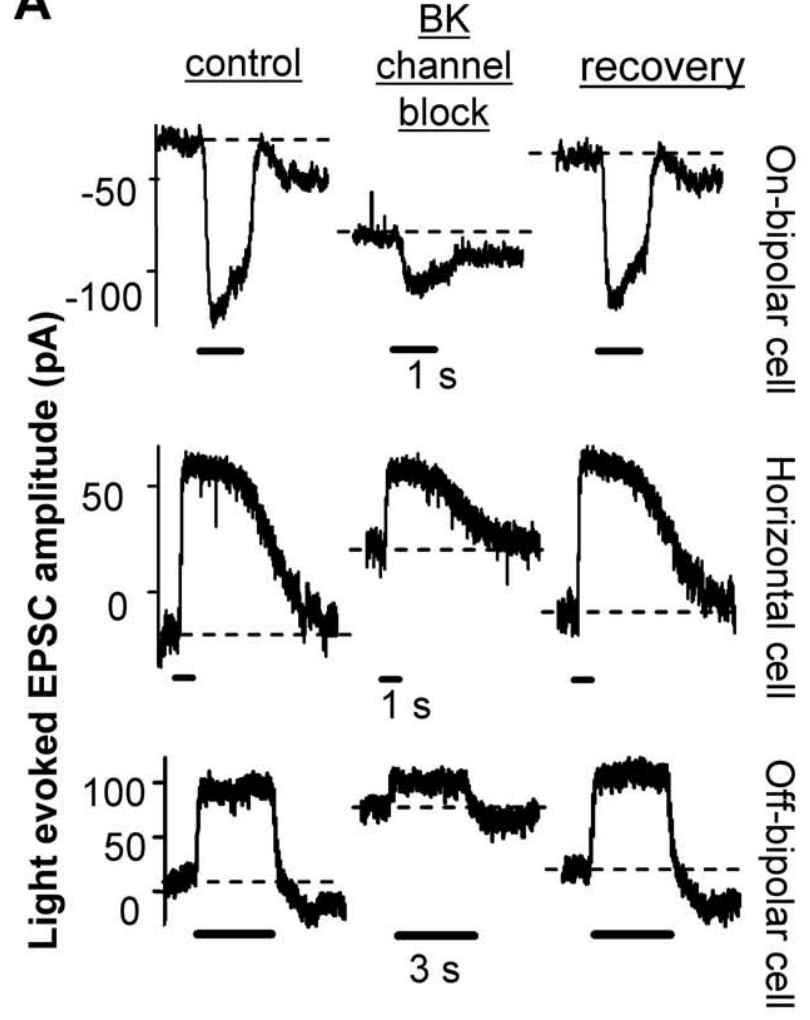

B

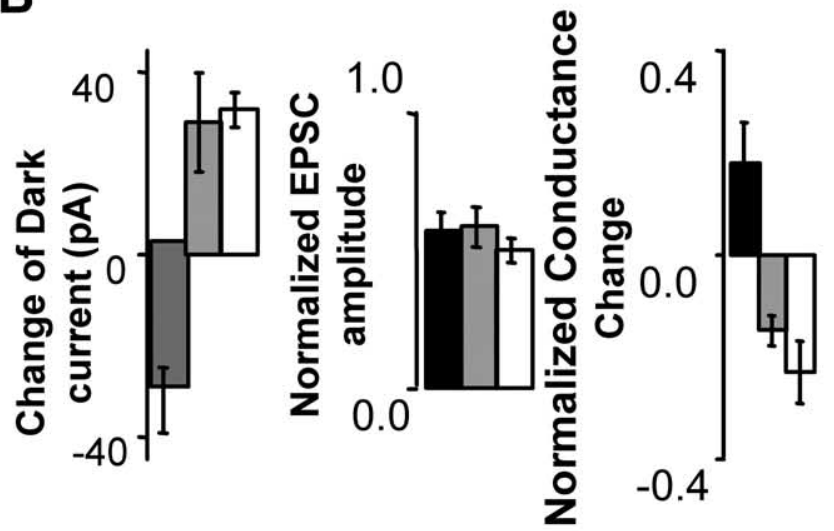

On-bipolar cell

Horizontal cell

Off-bipolar cell

Figure 2. BK channel block decreased transmitter release from rods. A, Rod-driven synaptic current responses of three types of neurons postsynaptic to rods. For each cell type, the left trace shows the control response, the middle trace shows the effect of a BK channel blocker, and the right trace shows recovery after removal of the blocker. All cells were held at $-60 \mathrm{mV}$ in dark-adapted retinal slices. The block made the dark holding current (dashed lines) more negative in On-bipolar cells and more positive in horizontal and Off-bipolar cells. Solid bars represent light stimuli. $\boldsymbol{B}$, Summary of the shift of dark holding current (left), suppression of lightevoked EPSC (middle; control as 1.0), and change of dark membrane conductance (right; control as 1.0) induced by BK blockers (On-bipolar, $n=7 ; 0$ Off-bipolar, $n=4$; horizontal cell, $n=4$ ). To measure the change in conductance, $\mathrm{a}-10 \mathrm{mV}$ pulse was applied to a cell in the dark $\left(V_{\text {hold }}=\right.$ $-60 \mathrm{mV})$, and the steady-state current was used as the indication of whole-cell conductance. The dark membrane conductance was decreased in horizontal and Off-bipolar cells and increased in On-bipolar cells. Error bars represent SE.
A
Grey trace: control
Black trace: 100 nM CTX

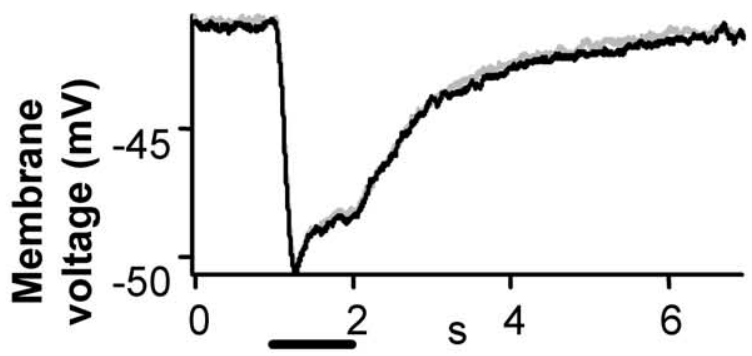

B
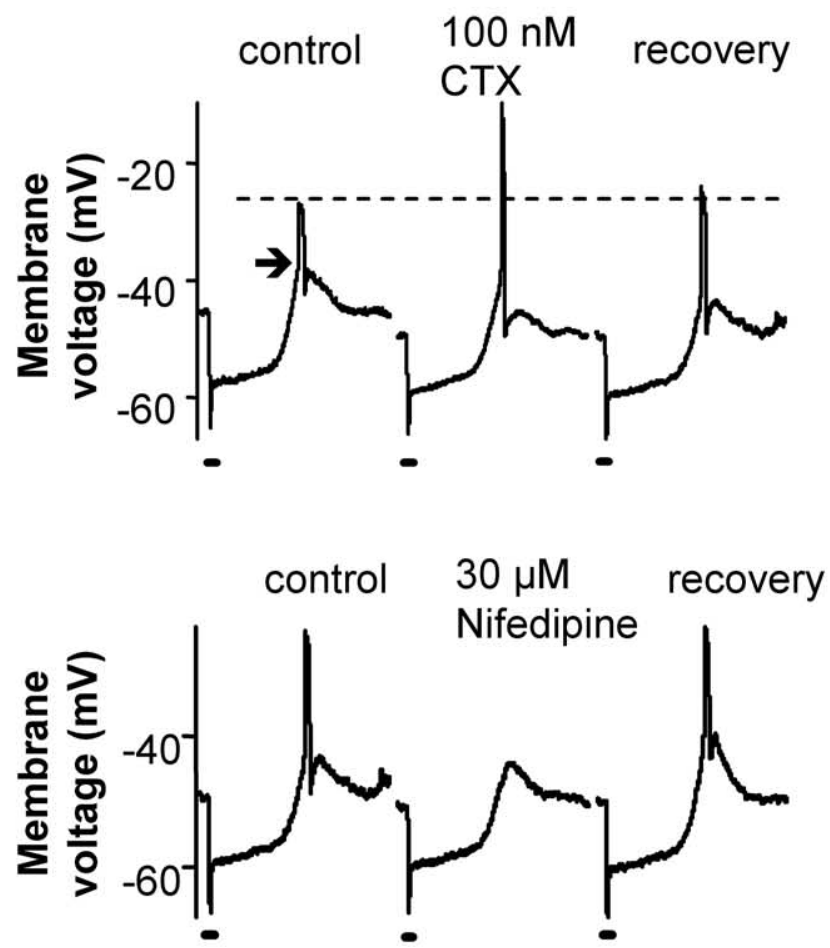

Figure 3. BK channel blocker effects on light-driven voltage responses of rods. $A, B K$ channel blockers had no significant effect on the light response of majority of rods ( 9 of 13). The light responses were recorded from rods in current-clamp mode in the dark-adapted retinal slice. The average dark $V_{\mathrm{m}}$ under control conditions was $-41.8 \pm 1.3 \mathrm{mV}$, and in the presence of $\mathrm{BK}$ channel blockers it was $-42.4 \pm 1.4 \mathrm{mV}(n=13)$. The solid bars represents the light stimulus. $B$, In some rods, the light response had an overshoot during the recovery phase (arrow; 4 of 13). BK blockers increased the peak of the overshoot (from $-27.6 \pm 2.7$ to $-17.4 \pm 3.0 \mathrm{mV} ; n=$ 4; top). The overshoot was blocked by L-type Ca channel blocker nifedipine (30 $\mu \mathrm{m} ; n=3$; bottom), suggesting it was a Ca spike. The solid bars represent $1 \mathrm{~s}$ light stimuli. All recordings were from dark-adapted retinal slices.

more depolarized voltages. The inward current is calcium current. The inward current cannot be Ca-dependent $\mathrm{K}$ or $\mathrm{Cl}$ current because $\mathrm{K}$ and $\mathrm{Cl}$ reversal potentials were set to -93 and -65 $\mathrm{mV}$, respectively. At more depolarized voltages, the net current was outward as a result of BK- and Ca-dependent $\mathrm{Cl}$ currents.

The current blocked by BK channel blockers was also biphasic (Fig. $4 B$, right). The blockers suppressed the inward current at voltages from -45 to $-30 \mathrm{mV}$ (Fig. $4 \mathrm{~B}$ ). This result indicates that 
A

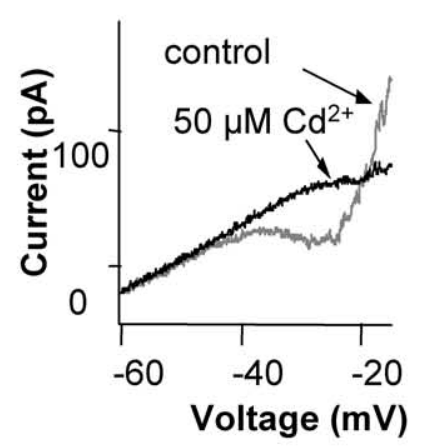

B

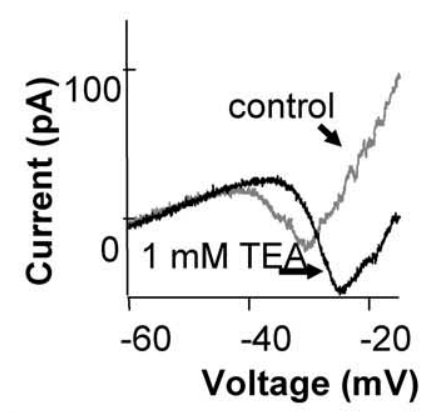

C

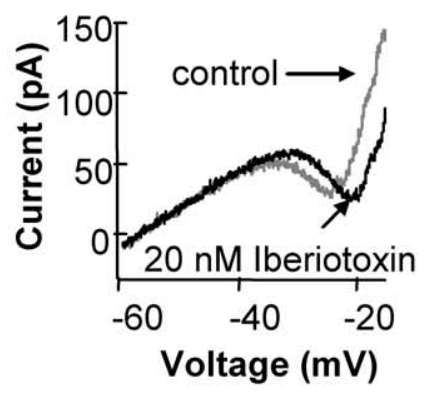

D
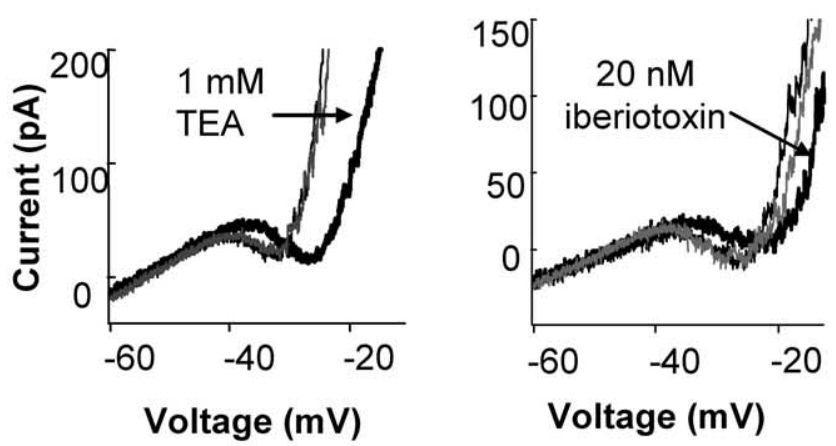

Figure 4. BK channel blockers suppressed Ca current in rods. $\boldsymbol{A}$, Ca current could be recorded in most rods in Ringer's solution. The left panel shows whole-cell current of a rod recorded during a voltage ramp (from -70 to $-10 \mathrm{mV}$, at $0.5 \mathrm{mV} / \mathrm{ms}$, with holding voltage of -50 $\mathrm{mV})$. In control, an inward current activated around $-45 \mathrm{mV}$ and reached peak around -25 $\mathrm{mV}$. At $-25 \mathrm{mV}$, an outward current rapidly activated. Both the inward and outward currents were blocked by $50 \mu \mathrm{m} \mathrm{Cd}^{2+}$. The right panel shows the subtraction of the control current and that in the presence of $50 \mu \mathrm{m} \mathrm{Cd}{ }^{2+}$, which represents the currents blocked by $50 \mu \mathrm{m} \mathrm{Cd}{ }^{2+}$, a Ca channel blocker. The blocked current was biphasic, inward when the voltage was negative to blocking BK channels also suppresses $I_{\mathrm{Ca}}$. There was a rightward shift in the apparent activation of the inward current in the presence of BK blockers, and it is tempting to suggest that BK channels shift the calcium channel activation to the left. However, because blockers could not be used to isolate the calcium current, this shift only indicates that the net inward current was altered. The inward current (Fig. $4 B$, right) is not pure Ca current but is the sum of $\mathrm{Ca}, \mathrm{BK}, \mathrm{Ca}$-activated $\mathrm{Cl}$, and voltage-gated $\mathrm{K}$ currents. Thus, the suppression of $I_{\mathrm{Ca}}$ was greater than the suppression of $I_{\mathrm{BK}}$ from -45 to $-30 \mathrm{mV}$. We considered the possibility that the terminal might not be well clamped, and hence the BK channel current may shift the calcium channel activation curve to the left by depolarizing the terminal. This is unlikely for two reasons. One is that rods are considered isopotential, and the small current produced when calcium channels first become activated is unlikely to cause a deterioration of the clamp. In addition, the BK channels follow the calcium current and therefore would not be expected to initiate the activation of calcium channels. At more positive voltages, BK channel blockers suppressed a net outward current, with the major component attributable to BK current. The same results were obtained by applying three different $\mathrm{BK}$ channel blockers: 1 mM TEA, 100 nM CTX, or 20 nM iberiotoxin. The effect of the blockers were reversible, as illustrated in Figure $4 D$. The effects of TEA were more rapidly and more completely reversible than that of the two toxins. The specificity of the blockers is described below and in Figure 7. Based on the specificity of these blockers, we conclude the effect was not caused by direct action on Ca channels but through BK channels.

Similar results were obtained in voltage step recordings (Fig. $5)$. When the cell was stepped to $-40 \mathrm{mV}$ from a holding potential of $-55 \mathrm{mV}$, an inward current developed, and it was suppressed by $1 \mathrm{mM}$ TEA. When the cell was stepped to higher voltages ( -30 and $-20 \mathrm{mV}$ ) (Fig. 5), the current suppressed by TEA had early and late components. The current suppressed was initially an inward $\mathrm{Ca}$ current. Then, the current suppressed was outward as the BK channels became the dominant current carriers. These results are similar to the observations in goldfish retinal bipolar cells (Sakaba et al., 1997).

Thus, BK channels have a biphasic action: enhancing inward calcium current at negative voltages (below $-30 \mathrm{mV}$ ) and producing an outward current at more positive voltages.

\section{Mechanism}

How do BK channels facilitate Ca current? Because of the large conductance of BK channels (150 pS) (Li et al., 2003) and the confined structure of the ribbon synapse (Townes-Anderson et al., 1985), potassium ions exiting the BK channel may accumulate in the synaptic cleft. The rod ribbon synapse is an invaginating synapse in which postsynaptic processes occupy the invagination in the rod spherule (Townes-Anderson et al., 1985). This creates a thin, sheet-like synaptic cleft between the rod spherule and the postsynaptic process, with a width $<10 \mathrm{~nm}$ and a distance of $>1$

$\leftarrow$

$-20 \mathrm{mV}$, and outward when positive to $-20 \mathrm{mV}$. The inward current blocked by $\mathrm{Cd}^{2+}$ was $\mathrm{Ca}$ current (see Results). Similar results were obtained in five rods. B, C, BK channel blockers $1 \mathrm{~mm}$ TEA $(n=5)$ or $20 \mathrm{~nm}$ iberiotoxin $(n=3)$ suppressed the Ca current. The current suppressed by BK channel blockers, obtained by subtracting the control current and the current, is shown on the right panels. From -45 to $-30 \mathrm{mV}$, BK channel blockers blocked an inward current. At more positive voltages, it suppressed an outward current. All recordings were from retinal slices. $D$, The effects of TEA and iberiotoxin were reversible. Ramps were applied under control conditions, then in the presence of TEA or iberiotoxin, and then again after removal of the blocker (gray traces). 


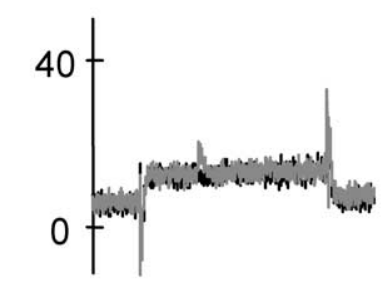

$$
\begin{aligned}
& \text { subtraction of } \\
& \text { control and in } \\
& 1 \mathrm{mM} \text { TEA }
\end{aligned}
$$
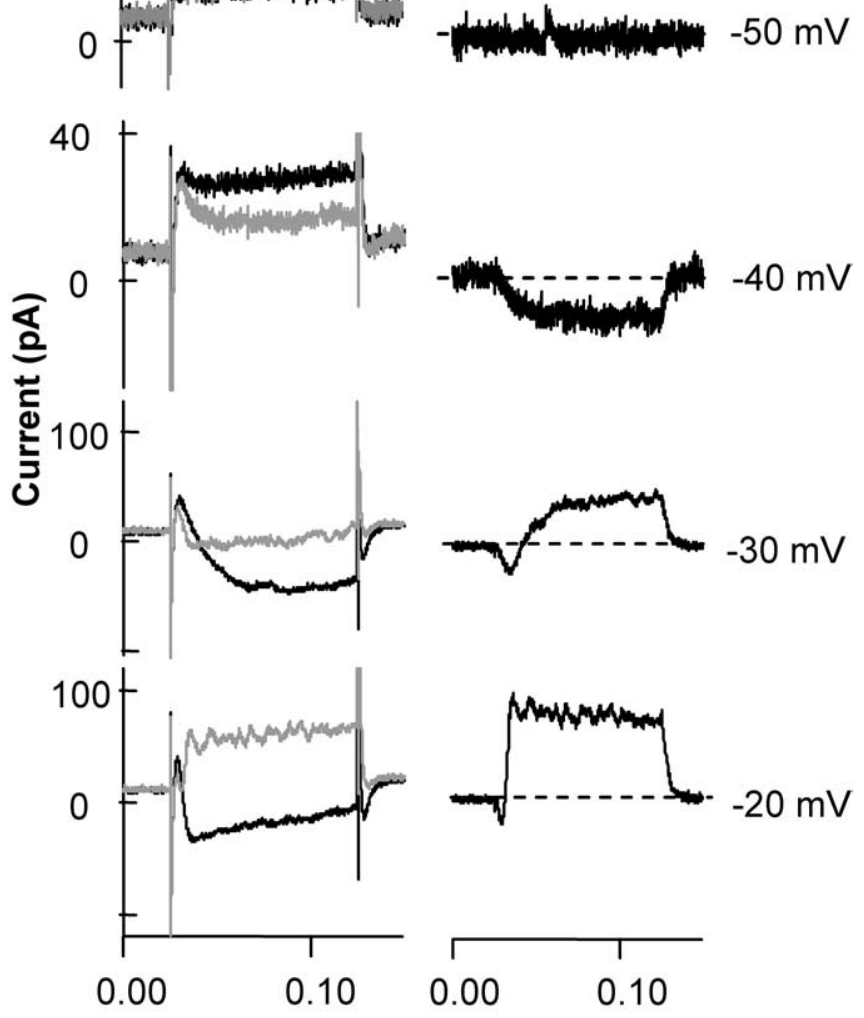

Time (s)

control

\section{1 mM TEA}

Figure 5. BK channel blockers produced a biphasic suppression of rod currents. The figure shows the current blocked by $1 \mathrm{~mm}$ TEA at different voltage steps. A rod from a retinal slice was voltage clamped and held at $-55 \mathrm{mV}$, then stepped to voltages from -70 to various voltages in increments of $10 \mathrm{mV}$ (step potentials are indicated). TEA, used at $1 \mathrm{~mm}$ to suppress BK channels, reduced an inward current at $-40 \mathrm{mV}$. When the step potential was $-30 \mathrm{mV}$ or higher, TEA suppressed an inward current at the beginning of the voltage step, then it suppressed an outward current. The left column shows the original data, and the right column shows the subtracted traces, isolating the TEA-sensitive current.

$\mu \mathrm{m}$ from the inner-most point in the cleft to the edge. The invagination has a narrow, $0.3 \mu \mathrm{m}$ neck (Townes-Anderson et al., 1985). The geometry of the cleft limits ion diffusion in the cleft. In physiological solution, it takes $\sim 1 \mathrm{~ms}$ for a particle to travel $1 \mu \mathrm{m}$ (Weiss, 1996). Therefore, on average, a particle will stay in the cleft for at least $1 \mathrm{~ms}$. We estimated that if one BK channel opens at the cleft, the mean potassium concentration inside the cleft will increase by $3 \mathrm{~mm}$ in $1 \mathrm{~ms}$ (see Materials and Methods).

At the dark membrane potential of $-40 \mathrm{mV}$ and $\left[\mathrm{Ca}^{2+}\right]_{\mathrm{i}}$ of 10 $\mu \mathrm{M}$, the $P_{\mathrm{o}}$ of BK channels is $\sim 0.05$ (Li et al., 2003). Therefore, at the terminal there may be as many as $10 \mathrm{BK}$ channels open $(N=$ $P_{\mathrm{o}} \times$ total number of channels $\left.=0.05 \times 200\right)$. The whole synaptic terminal can be approximated by a $2-\mu \mathrm{m}$-diameter outer ball and a $1-\mu \mathrm{m}$-diameter inner ball that form the extracellular environment of the ribbon synapse (Townes-Anderson et al., 1985). Assuming an even distribution of the channels, the inner ball contains $\sim 40$ BK channels, among which an average of two chan-
A

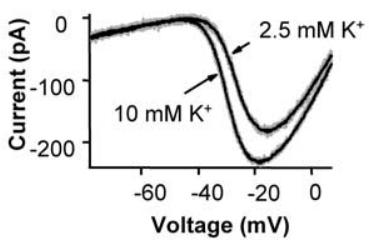

C

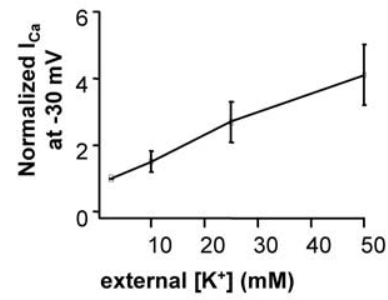

B

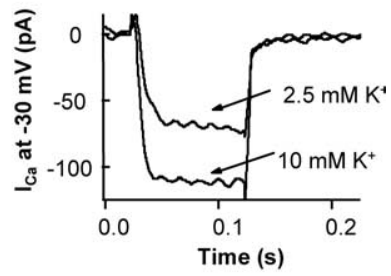

D

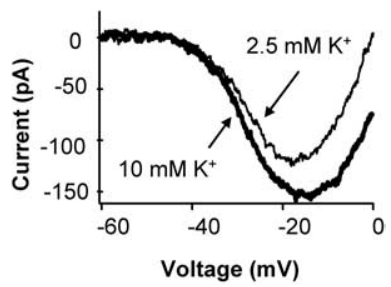

Figure 6. Increasing $\left[\mathrm{K}^{+}\right]_{0}$ increased the voltage-activated calcium current ins rods. $\boldsymbol{A}$, When $\left[\mathrm{K}^{+}\right]_{0}$ was increased from 2.5 to $10 \mathrm{~mm}$ while keeping total ion concentration unchanged, Ca current was increased. $I_{\text {Ca }}$ was obtained by a voltage ramp (from -80 to $10 \mathrm{mV}$, at $0.5 \mathrm{mV} / \mathrm{ms})$. Potassium channels were blocked by $40 \mathrm{~mm}$ TEA-Cl, and $I_{\mathrm{h}}$ was blocked by $5 \mathrm{~mm}$ $\mathrm{CSCl}$. The black traces were the average of four traces each. $B$, Ca current at $-30 \mathrm{mV}\left(V_{\text {hold }}=\right.$ $-55 \mathrm{mV}$ ) was increased when $\left[\mathrm{K}^{+}\right]_{0}$ was increased from 2.5 to $10 \mathrm{~mm}$. The average increase of $I_{\text {Ca }}$ at $-30 \mathrm{mV}$ when $\left[\mathrm{K}^{+}\right]_{0}$ was increased from 2.5 to $10 \mathrm{~mm}(n=8)$ was $50 \pm 12 \%$. C, Plot of Ca current measured at $-30 \mathrm{mV}$ with various concentrations of extracellular potassium: $\left[\mathrm{K}^{+}\right]_{0}$ of $2.5,10,25$, and $50 \mathrm{~mm}(n=4)$. The $\mathrm{Ca}$ current at different $\left[\mathrm{K}^{+}\right]_{0}$ was normalized to its amplitude at $2.5 \mathrm{~mm}\left[\mathrm{~K}^{+}\right]_{0}$. Data in $A-C$ we from recordings in retinal slices. Error bars represent SE. $D$, The calcium current was measured in an intact isolated rod using $40 \mathrm{~mm}$ TEA and $5 \mathrm{~mm}$ $\mathrm{CsCl}$ in the extracellular solution and applying a ramp stimulus from -70 to $0 \mathrm{mV}(0.9 \mathrm{mV} / \mathrm{ms})$. The ramp stimulus was applied with 2.5 and $10 \mathrm{~mm}\left[\mathrm{~K}^{+}\right]_{0}$.

nels might be open in the dark. This could raise mean extracellular potassium by $\sim 6 \mathrm{~mm}$ in the synaptic cleft. Because the concentration distribution caused by diffusion follows a Gaussian function, with the highest concentration at the BK channel, local concentrations near the calcium channel would be higher than the mean because of apposition of BK and Ca channels. Thus, calcium channels might be regulated by BK channel activity if they were sensitive to extracellular potassium concentration.

To test whether increasing $\left[\mathrm{K}^{+}\right]$in the cleft enhanced $I_{\mathrm{Ca}}$, we recorded the calcium current in rods in retinal slices in 2.5 and 10 $\mathrm{mM}\left[\mathrm{K}^{+}\right]_{\mathrm{o}}$. In these recordings, all potassium channels were blocked by $40 \mathrm{~mm}$ TEA chloride, and $I_{\mathrm{h}}$ current was blocked by 5 $\mathrm{mm}$ CsCl. The voltage-activated calcium current of the rod was augmented when extracellular potassium was raised (Fig. 6). The current increase was evident in both ramp (Fig. 6A) and voltagestep protocols (Fig. $6 \mathrm{~B}$ ). In $10 \mathrm{mM}\left[\mathrm{K}^{+}\right]_{0}$, the Ca current was $1.78 \pm 0.16$ times that in $2.5 \mathrm{~mm}\left[\mathrm{~K}^{+}\right]_{\mathrm{o}}$ at $-40 \mathrm{mV}$ and $1.50 \pm$ 0.12 times larger at $-30 \mathrm{mV}(n=8)$. These results indicate that raising extracellular $\left[\mathrm{K}^{+}\right]$can enhance Ca current in rods.

The Ca currents were measured at several concentrations of extracellular K. Figure $6 \mathrm{C}$ shows the results of rod Ca current in $\left[\mathrm{K}^{+}\right]_{\mathrm{o}}$ of $2.5,10,25$, and $50 \mathrm{~mm}$, recorded from rods held at -30 $\mathrm{mV}$ in retinal slices $(n=4)$. The Ca current increased with increasing concentration of $\left[\mathrm{K}^{+}\right]_{\mathrm{o}}$. The Ca currents at 2.5, 10, 25, and $50 \mathrm{~mm}\left[\mathrm{~K}^{+}\right]_{\mathrm{o}}$ were $1.0,1.5 \pm 0.3,2.7 \pm 0.7$, and $4.1 \pm 0.9$, respectively, normalized to $\left[\mathrm{K}^{+}\right]_{\mathrm{o}}$ of $2.5 \mathrm{~mm}$. Thus, extracellular $\mathrm{K}$ increases $\mathrm{Ca}$ current in a concentration-dependent manner.

Increasing extracellular potassium in the retinal slice raises the possibility that the alteration in calcium current might be caused by a potassium-induced depolarization of second-order neurons and an indirect, transsynaptic effect on the rod. To test this pos- 
sibility, rods with intact synaptic terminals were isolated and the effects of high potassium were tested on single cells. To monitor the calcium current, the extracellular solution contained $40 \mathrm{mM}$ TEA-Cl and $5 \mathrm{~mm} \mathrm{CsCl}$ to block voltage-gated potassium and $I_{\mathrm{h}}$ currents, respectively. Raising extracellular calcium from 2.5 to $10 \mathrm{~mm}$ increased the peak calcium current by $33 \pm 2 \%(n=2)$ (Fig. 6D). Changing extracellular potassium from nominally potassium-free to $10 \mathrm{~mm}$ potassium increased peak calcium current by $75 \pm 29 \%(n=2)$. Thus, the effect of elevating extracellular potassium persisted when rods were isolated from the retinal network.

Our model proposes that BK channel activity increases the extracellular K concentration in the synaptic cleft, which in turn increases Ca channel current and hence synaptic transmission. In this model, the synaptic cleft is important for the facilitation to occur. For isolated cells, the synaptic cleft and the diffusion barrier no longer exist. Then one would expect that blocking BK channels would have little effect on the Ca channel current. To test this idea, we recorded the $I-V$ of isolated rods in control Ringer's solution using a voltage-ramp protocol. The $I-V$ of the isolated rods had similar shape to that of rods in slices. The major difference is that the inward Ca current in the voltage range from -40 to $-20 \mathrm{mV}$ was smaller in isolated cells even when they had intact synaptic terminals ( 5 of 28 ), compared with rods in retinal slices ( 17 of 20). One possible explanation is that the intracellular calcium concentration in terminals of isolated rods is higher than in rod terminals in slices (Shen and Slaughter, 1999). As a result, during depolarization, more BK channels are activated and mask the inward Ca current. This may explain the different actions of BK channel blockers on rod voltage and light responses in our study and that by Moriondo et al. (2001) (see Discussion). In all the isolated rods tested, BK channel blockers always suppressed outward current at the activation range of BK channels $(n=5)$ (Fig. 7A) and did not suppress inward current, in contrast to rods in retinal slices (Fig. $4 B, C$ ). These results demonstrate that the synaptic cleft is required for the suppression of Ca current by BK channel blockers. It supports a model in which a restricted extracellular geometry is required for the facilitation of Ca current by BK channels.

One concern is that BK channel blockers do not act through specific inhibition of BK channels but directly suppress Ca channels. Charybdotoxin and iberiotoxin are reputed to be specific toxins on BK channels and not to affect L-type Ca channels (Hermann and Erxleben, 1987; Galvez et al., 1990). One millimolar TEA is also selective for BK channels and has little effect on many other K channels (Iwatsuki and Petersen, 1985; Kros et al., 1998). We tested whether these BK blockers have a nonspecific action on calcium channels in rods. Ca currents were recorded in isolated rods. $\mathrm{Ba}(5 \mathrm{~mm})$ in the external solution served as the charge carrier of Ca channel current and to block BK current. The pipette solution contained Cs-methanesulfonate in place of K-gluconate to further suppress $\mathrm{K}$ currents and contained $10 \mathrm{mM}$ BAPTA to uncouple the activation of BK channels and $\mathrm{Ca}$ ( $\mathrm{Ba}$ in this case) entry. We then applied each of the three BK channel blockers, and none of them had effects on the Ca channel current $(n=4)$ (Fig. $7 B$ ). These results indicate that these BK channel blockers do not directly affect $\mathrm{Ca}$ channels. Their action on $\mathrm{Ca}$ channels and transmitter release is indirect and likely through action on BK channels.

\section{Discussion}

Our results suggest that the BK channel enhances calcium current by increasing extracellular potassium concentration in the syn-

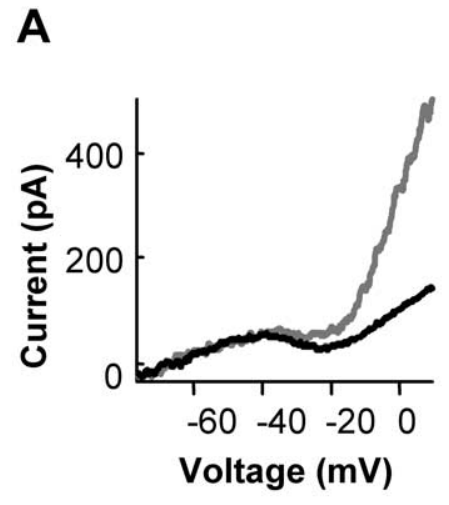

B

\section{- control \\ - $20 \mathrm{nM}$ iberiotoxin}

Figure 7. BK channel blockers had no direct effect on Ca channels. $\boldsymbol{A}$, BK channel block does not suppress the Ca current in isolated rods. The $I-V$ of isolated rods with synaptic terminals was obtained by a voltage ramp (from -70 to $20 \mathrm{mV}$, at $0.5 \mathrm{mV} / \mathrm{ms}$, with holding potential of -50 $\mathrm{mV})$. The $I-V$ in control conditions was recorded when the cell was perfused with Ringer's solution and K-gluconate was the main salt of the internal solution (gray trace). The BK channel blocker $20 \mathrm{~nm}$ iberiotoxin suppressed outward current. $\boldsymbol{B}$, BK channel blockers had no direct effect on Ca channel current. Ca channel current was recorded in isolated rods with terminals. The internal solution contained $100 \mathrm{~mm}$ Cs methanesulfonate and $10 \mathrm{~mm}$ BAPTA to suppress BK current. Five millimolar Ba was in the external solution to replace Ca as the charge carrier and to suppress K current. Iberiotoxin ( $20 \mathrm{~nm}$ ) had no significant effect on the calcium current. Other BK channel blockers ( $1 \mathrm{~mm}$ TEA and $100 \mathrm{~nm}$ (TX) were also without effect on the calcium current in isolated rods (data not shown).

aptic cleft. Ca current of rods increases with extracellular $\mathrm{K}$ in a concentration-dependent manner. We propose that there is a low-affinity K binding site at the extracellular side of the Ca channel that enhances channel activity. This is in accord with studies showing that extracellular monovalent ion concentration can affect channel properties. Increasing $\left[\mathrm{K}^{+}\right]_{\mathrm{o}}$ can change channel conductance in delayed rectifier K channels (Shibasaki, 1987), mean open time of the NMDA channels (Ozawa et al., 1990), and C-type inactivation of Kv1.4 (Baukrowitz and Yellen, 1995).

Changes in local extracellular ion concentration may be a common regulatory mechanism at synapses with geometrically restricted synaptic clefts as a result of the diffusion barrier created by its confined structure. Proton and calcium concentration inside the synaptic cleft change during transmission, which regulates Ca channels at the ribbon synapses (Barnes et al., 1993; DeVries, 2001; Rabl and Thoreson, 2002). The different effects of BK channel blockers on the $I-V$ curves of the rods in slices and isolated rods strongly suggests the importance of synaptic cleft in calcium current enhancement.

Elevated $\mathrm{K}_{\mathrm{o}}$ may depolarize the rod terminal, also leading to a facilitation of transmitter release. This should not be applicable in our voltage-clamp experiments but may be an important additional factor in the normal physiology of the rod. Thus, as BK channels open, they can facilitate calcium channel activation by both binding to the channel and by the voltage-dependent stimulation of the channel.

We demonstrated that the BK channel blockers 1 mM TEA, 20 nM iberiotoxin, and $100 \mathrm{~nm}$ charybdotoxin suppressed Ca channel current. This effect was not directly on Ca channels, nor is it likely that these agents affect the voltage sensitivity of Ca channels by changing the surface potential of the rods.

Our results indicate that the BK channel and the calcium 
channel form a positive coupled loop. BK channel activity normally leads to membrane hyperpolarization. However, the linkage between the BK current and calcium channel current at the rod synapse is finely tuned, and the two opposing currents approximately balance. Thus, suppression of the BK current reduces the calcium current without altering the overall membrane voltage of the rod. This enables the amplification of signal transmission without altering membrane voltage. Hence, the relationship between the activity of light sensitive channels and the membrane potential is maintained.

Moriondo et al. (2001) found that BK channel blockers depolarized isolated rods by up to $30 \mathrm{mV}$ and concluded that $\mathrm{BK}$ channels clamped the membrane potential of rods. In our study, BK channel blockers had no effect on the dark membrane voltage or light response of most rods in retinal slices. One possible explanation for this discrepancy is that the Ca concentration in the isolated rods is higher than in rods from the retinal slice. This effect of cell isolation has been observed in ganglion cells (Shen and Slaughter, 1999). Therefore, at depolarized voltages, there may be more BK channels open in isolated rods because of the elevated Ca level. Additionally, Moriondo et al. (2001) depolarized rods to $-35 \mathrm{mV}$ or more to see the depolarizing effect of BK channel blockers. This is consistent with our results at more depolarized rod potentials. Furthermore, when action potentials were generated (Fig. 3), we observed that the hyperpolarizing effect of BK channels overwhelmed their facilitation of $\mathrm{Ca}$ channels.

The enhancement of Ca current by the positive coupling of BK and $\mathrm{Ca}$ channels is important for the rod signal. Through this coupling, the overall transmission from a rod to second-order neurons is amplified. The degree of the coupling depends on ion concentrations and hence membrane depolarization. Therefore, this enhancement is nonlinear, with a bigger amplification at more depolarized voltages. This conforms to the function of the rod: to respond to weak light stimuli. Small light responses, which correspond to small hyperpolarizations in depolarized rods, are amplified maximally. This is consistent with the nonlinear characteristics of amphibian rod signal transmission (Witkovsky et al., 1997). Additionally, it serves as an intrinsic adaptation mechanism.

To maximize the signal output of a neuron at a set voltage, the simplest solution is a high density of Ca channels. However, this may lead to regenerative Ca spikes. The BK-Ca channel loop can enhance calcium influx while minimizing the net current at the terminal. The coupling between BK and calcium channels is also in excellent alignment with the physiological response range of the rod. If the rod is depolarized beyond this range, then the BK current overwhelms all other currents and hyperpolarizes the cell (Fig. 3B). This may serve as a safety break.

The paired coupling may be a key feature of transmitter release in neurons that rely on graded potentials, such as sensory receptors. In spiking systems, such as neuromuscular junctions of Xenopus, BK channel blockers did not affect the presynaptic action potential but decreased transmitter release (Pattillo et al., 2001). This result implies that the same mechanism may also apply to the spiking neurons. This mechanism, combined with the effect of BK channels on the action potential shape in the soma of some spiking neurons, may explain the conflicting results of previous studies (Robitaille et al., 1993; Marshall et al., 1994; Warbington et al., 1996; Pattillo et al., 2001; Wang et al., 2001; Skinner et al., 2003). However, this needs to be tested in other systems.

In summary, we found that BK channels are concentrated at the synaptic terminal of rods, along with L-type Ca channels. They facilitate transmitter release from rods by enhancing Ca currents. Their activity produces an increase of local $\left[\mathrm{K}^{+}\right]_{\mathrm{o}}$ near Ca channels, which enhances Ca channel current. Therefore, the positive feedback between the two channels amplifies synaptic transmission yet still provides for a safety brake.

\section{References}

Attwell D, Werblin FS, Wilson M, Wu SM (1983) A sign-reversing pathway from rods to double and single cones in the retina of the tiger salamander. J Physiol (Lond) 336:313-333.

Awatramani GB, Slaughter MM (2000) Origin of transient and sustained responses in ganglion cells of the retina. J Neurosci 20:7087-7095.

Barnes S, Hille B (1989) Ionic channels of the inner segment of tiger salamander cone photoreceptors. J Gen Physiol 94:719-743.

Barnes S, Merchant V, Mahmud F (1993) Modulation of transmission gain by protons at the photoreceptor output synapse. Proc Natl Acad Sci USA 90:10081-10085.

Baukrowitz T, Yellen G (1995) Modulation of $\mathrm{K}^{+}$current by frequency and external $\left[\mathrm{K}^{+}\right]$: a tale of two inactivation mechanisms. Neuron 15: 951-960.

Christie MJ, North RA, Osborne PB, Douglass J, Adelman JP (1990) Heteropolymeric potassium channels expressed in Xenopus oocytes from cloned subunits. Neuron 4:405-411.

DeVries SH (2001) Exocytosed protons feedback to suppress the $\mathrm{Ca}^{2+}$ current in mammalian cone photoreceptors. Neuron 32:1107-1117.

Galvez A, Gimenez-Gallego G, Reuben JP, Roy-Contancin L, Feigenbaum P, Kaczorowski GJ, Garcia ML (1990) Purification and characterization of a unique, potent, peptidyl probe for the high conductance calciumactivated potassium channel from venom of the scorpion Buthus tamulus. J Biol Chem 265:11083-11090.

Grissmer S, Nguyen AN, Cahalan MD (1993) Calcium-activated potassium channels in resting and activated human T lymphocytes. Expression levels, calcium dependence, ion selectivity, and pharmacology. J Gen Physiol 102:601-630

Grissmer S, Nguyen AN, Aiyar J, Hanson DC, Mather RJ, Gutman GA, Karmilowicz MJ, Auperin DD, Chandy KG (1994) Pharmacological characterization of five cloned voltage-gated $\mathrm{K}^{+}$channels, types Kv1.1, $1.2,1.3,1.5$, and 3.1, stably expressed in mammalian cell lines. Mol Pharmacol 45:1227-1234.

Hadley JK, Noda M, Selyanko AA, Wood IC, Abogadie FC, Brown DA (2000) Differential tetraethylammonium sensitivity of KCNQ1-4 potassium channels. Br J Pharmacol 129:413-415.

Heidelberger R, Heinemann C, Neher E, Matthews G (1994) Calcium dependence of the rate of exocytosis in a synaptic terminal. Nature 371:513-515.

Hensley SH, Yang XL, Wu SM (1993) Relative contribution of rod and cone inputs to bipolar cells and ganglion cells in the tiger salamander retina. J Neurophysiol 69:2086-2098.

Hermann A, Erxleben C (1987) Charybdotoxin selectively blocks small Caactivated K channels in Aplysia neurons. J Gen Physiol 90:27-47.

Hu H, Shao LR, Chavoshy S, Gu N, Trieb M, Behrens R, Laake P, Pongs O, Knaus HG, Ottersen OP, Storm JF (2001) Presynaptic $\mathrm{Ca}^{2+}$-activated $\mathrm{K}^{+}$channels in glutamatergic hippocampal terminals and their role in spike repolarization and regulation of transmitter release. J Neurosci 21:9585-9597.

Iwatsuki N, Petersen $\mathrm{OH}$ (1985) Action of tetraethylammonium on calcium-activated potassium channels in pig pancreatic acinar cells studied by patch-clamp single-channel and whole-cell current recording. J Membr Biol 86:139-144.

Katz B, Miledi R (1968) The role of calcium in neuromuscular facilitation. J Physiol (Lond) 195:481-492.

Knaus HG, Schwarzer C, Koch RO, Eberhart A, Kaczorowski GJ, Glossmann H, Wunder F, Pongs O, Garcia ML, Sperk G (1996) Distribution of high-conductance $\mathrm{Ca}^{2+}$-activated $\mathrm{K}^{+}$channels in rat brain: targeting to axons and nerve terminals. J Neurosci 16:955-963.

Kros CJ, Ruppersberg JP, Rusch A (1998) Expression of a potassium current in inner hair cells during development of hearing in mice. Nature 394:281-284.

Lancaster B, Nicoll RA (1987) Properties of two calcium-activated hyperpolarizations in rat hippocampal neurones. J Physiol (Lond) 389:187-203.

Li P, Keleshian AM, Slaughter MM (2003) Calcium-activated, large con- 
ductance potassium channels in retinal neurons. Paper presented at the 76th Annual Meeting of the Association for Research in Vision and Ophthalmology, Ft. Lauderdale, FL, May.

Lindgren CA, Moore JW (1989) Identification of ionic currents at presynaptic nerve endings of the lizard. J Physiol (Lond) 414:201-222.

Llobet A, Cooke A, Lagnado L (2003) Exocytosis at the ribbon synapse of retinal bipolar cells studied in patches of presynaptic membrane. J Neurosci 23:2706-2714.

MacKinnon R, Reinhart PH, White MM (1988) Charybdotoxin block of Shaker $\mathrm{K}^{+}$channels suggests that different types of $\mathrm{K}^{+}$channels share common structural features. Neuron 1:997-1001.

Marshall DL, Vatanpour H, Harvey AL, Boyot P, Pinkasfeld S, Doljansky Y, Bouet F, Menez A (1994) Neuromuscular effects of some potassium channel blocking toxins from the venom of the scorpion Leiurus quinquestriatus hebreus. Toxicon 32:1433-1443.

Meir A, Ginsburg S, Butkevich A, Kachalsky SG, Kaiserman I, Ahdut R, Demirgoren S, Rahamimoff R (1999) Ion channels in presynaptic nerve terminals and control of transmitter release. Physiol Rev 79:1019-1088.

Miller C, Moczydlowski E, Latorre R, Phillips M (1985) Charybdotoxin, a protein inhibitor of single $\mathrm{Ca}^{2+}$-activated $\mathrm{K}^{+}$channels from mammalian skeletal muscle. Nature 313:316-318.

Mitra P, Slaughter MM (2002) Mechanism of generation of spontaneous miniature outward currents (SMOCs) in retinal amacrine cells. J Gen Physiol 119:355-372.

Moriondo A, Pelucchi B, Rispoli G (2001) Calcium-activated potassium current clamps the dark potential of vertebrate rods. Eur J Neurosci 14:19-26.

Ozawa S, Iino M, Tsuzuki K (1990) Suppression by extracellular $\mathrm{K}^{+}$of $\mathrm{N}$-methyl-D-aspartate responses in cultured rat hippocampal neurons. J Neurophysiol 64:1361-1367.

Pattillo JM, Yazejian B, DiGregorio DA, Vergara JL, Grinnell AD, Meriney SD (2001) Contribution of presynaptic calcium-activated potassium currents to transmitter release regulation in cultured Xenopus nerve-muscle synapses. Neuroscience 102:229-240.

Rabl K, Thoreson WB (2002) Calcium-dependent inactivation and depletion of synaptic cleft calcium ions combine to regulate rod calcium currents under physiological conditions. Eur J Neurosci 16:2070-2077.

Rieke F, Schwartz EA (1996) Asynchronous transmitter release: control of exocytosis and endocytosis at the salamander rod synapse. J Physiol (Lond) 493: 1-8.

Robitaille R, Garcia ML, Kaczorowski GJ, Charlton MP (1993) Functional colocalization of calcium and calcium-gated potassium channels in control of transmitter release. Neuron 11:645-655.
Rosenberg RL, Hess P, Tsien RW (1988) Cardiac calcium channels in planar lipid bilayers. L-type channels and calcium-permeable channels open at negative membrane potentials. J Gen Physiol 92:27-54.

Sakaba T, Ishikane H, Tachibana M (1997) $\mathrm{Ca}^{2+}$-activated $\mathrm{K}^{+}$current at presynaptic terminals of goldfish retinal bipolar cells. Neurosci Res 27:219-228.

Shao LR, Halvorsrud R, Borg-Graham L, Storm JF (1999) The role of BKtype $\mathrm{Ca}^{2+}$-dependent $\mathrm{K}^{+}$channels in spike broadening during repetitive firing in rat hippocampal pyramidal cells. J Physiol (Lond) 521:135-146.

Shen W, Slaughter MM (1999) Internal calcium modulates apparent affinity of metabotropic GABA receptors. J Neurophysiol 82:3298-3306.

Shibasaki T (1987) Conductance and kinetics of delayed rectifier potassium channels in nodal cells of the rabbit heart. J Physiol (Lond) 387:227-250.

Skinner LJ, Enee V, Beurg M, Jung HH, Ryan AF, Hafidi A, Aran JM, Dulon D (2003) Contribution of $\mathrm{BK} \mathrm{Ca}^{2+}$-activated $\mathrm{K}^{+}$channels to auditory neurotransmission in the Guinea pig cochlea. J Neurophysiol 90: 320-332.

Storm JF (1987a) Action potential repolarization and a fast afterhyperpolarization in rat hippocampal pyramidal cells. J Physiol (Lond) 385:733-759.

Storm JF (1987b) Intracellular injection of a $\mathrm{Ca}^{2+}$ chelator inhibits spike repolarization in hippocampal neurons. Brain Res 435:387-392.

Thoreson WB, Nitzan R, Miller RF (2000) Chloride efflux inhibits single calcium channel open probability in vertebrate photoreceptors: chloride imaging and cell-attached patch-clamp recordings. Vis Neurosci 17: 197-206.

Townes-Anderson E, MacLeish PR, Raviola E (1985) Rod cells dissociated from mature salamander retina: ultrastructure and uptake of horseradish peroxidase. J Cell Biol 100:175-188.

Wang ZW, Saifee O, Nonet ML, Salkoff L (2001) SLO-1 potassium channels control quantal content of neurotransmitter release at the C. elegans neuromuscular junction. Neuron 32:867-881.

Warbington L, Hillman T, Adams C, Stern M (1996) Reduced transmitter release conferred by mutations in the slowpoke-encoded $\mathrm{Ca}^{2+}$-activated $\mathrm{K}^{+}$channel gene of Drosophila. Invert Neurosci 2:51-60.

Weiss TF (1996) Cellular biophysics, Vol I, Transport, pp 104-105. Cambridge, MA: MIT.

Witkovsky P, Schmitz Y, Akopian A, Krizaj D, Tranchina D (1997) Gain of rod to horizontal cell synaptic transfer: relation to glutamate release and a dihydropyridine-sensitive calcium current. J Neurosci 17:7297-7306.

Wollmut LP, Hille B (1992) Ionic selectivity of Ih channels of rod photoreceptors in tiger salamanders. J Gen Physiol 100:749-765.

Wu SM (1987) Synaptic connections between neurons in living slices of the larval tiger salamander retina. J Neurosci Methods 20:139-149. 